\title{
Real-Time Glucose Sensors in Children and Adolescents with Type-1 Diabetes
}

\author{
Thomas Danne $^{\mathrm{a}}$ Karin Lange ${ }^{\mathrm{b}}$ Olga Kordonouri ${ }^{\mathrm{a}}$ \\ a Kinderkrankenhaus auf der Bult, and b Department of Medical Psychology, Medizinische Hochschule Hannover, \\ Hannover, Germany
}

Key Words

Glucose sensors, real-time $\cdot$ Diabetes therapy

\begin{abstract}
The increased availability of continuous glucose sensors is likely to have a significant impact on pediatric diabetes therapy and education in the future. While a recent meta-analysis of retrospective first-generation Holter-type sensors was not able to show advantages compared to self-monitoring of blood glucose levels, this review focuses on current realtime sensors. Our own experience with 23 children aged 10 (3-15) years with sensor-augmented pump therapy showed high ratings for overall satisfaction and ease of use of the system (5.8 on a 7 point Likert scale). The results of our ongoing international pediatric ONSET trial will show the impact of this technology on learning to live with diabetes by having the biofeedback of glucose excursions from the onset of diabetes. Families previously relying on self-monitoring of blood glucose need to understand the difference between estimating the absolute blood glucose value (point accuracy) and the change in blood glucose (rate accuracy), and how to take into consideration the inherent interstitial time lag. Selection of patients capable and motivated to use continuous sensors accompanied with proper age-appropriate education remain key factors for the long-term success of these new technological advances in diabetes therapy as long as closed loop systems are not available.
\end{abstract}

Copyright $\odot 2008$ S. Karger AG, Basel

\section{Introduction}

While HbA1c for the time being remains the gold standard for assessing the risk for late complications also in pediatric patients $[1,2]$, it has obvious limits as it is only a parameter for average glucose levels. There is substantial variability in individual mean glucose concentrations for a given Alc. Utilizing continuous glucose monitoring (CGM) data to examine the relationship between A1c and glucose levels in 48 youths with type-1 diabetes found a slope of mean glucose over the previous 3 months vs. Alc of only $18 \mathrm{mg} / \mathrm{dl}$ per $1.0 \%$ Alc [3].

Evidence is building relating to the importance of glycemic variability for various outcomes in type-1 diabetes. For example, in a recent meta-analysis of four trials with the long-acting insulin detemir, a significant correlation between the inpatient variability (coefficient of variation) of fasting blood glucose and the rate of hypoglycemia was found [4]. In patients with type-2 diabetes a significant association of the mean amplitude of glycemic excursions (MAGEs), an established parameter for glycemic variability [5], and urinary 8-iso-PGF2 $\alpha$, a parameter related to superoxide overproduction, and the subsequent development of later complications was reported [6]. This suggests that different therapeutic strategies now in use [7] should be evaluated for their potential to minimize glycemic excursion, as well as their ability to lower Alc. Therefore, wider use of real-time CGM in clinical practice would provide the required monitoring tool to mini-

\section{KARGER}

Fax +4161306 1234 E-Mail karger@karger.ch www.karger.com
(C) 2008 S. Karger AG, Basel

0301-0163/08/0704-0193\$24.50/0

Accessible online at:

www.karger.com/hre
Thomas Danne

Kinderkrankenhaus auf der Bult

Janusz-Korczak-Allee 12

DE-30173 Hannover (Germany)

Tel. +49 5118115 3330, Fax +49 5118115 3334, E-Mail Danne@hka.de 


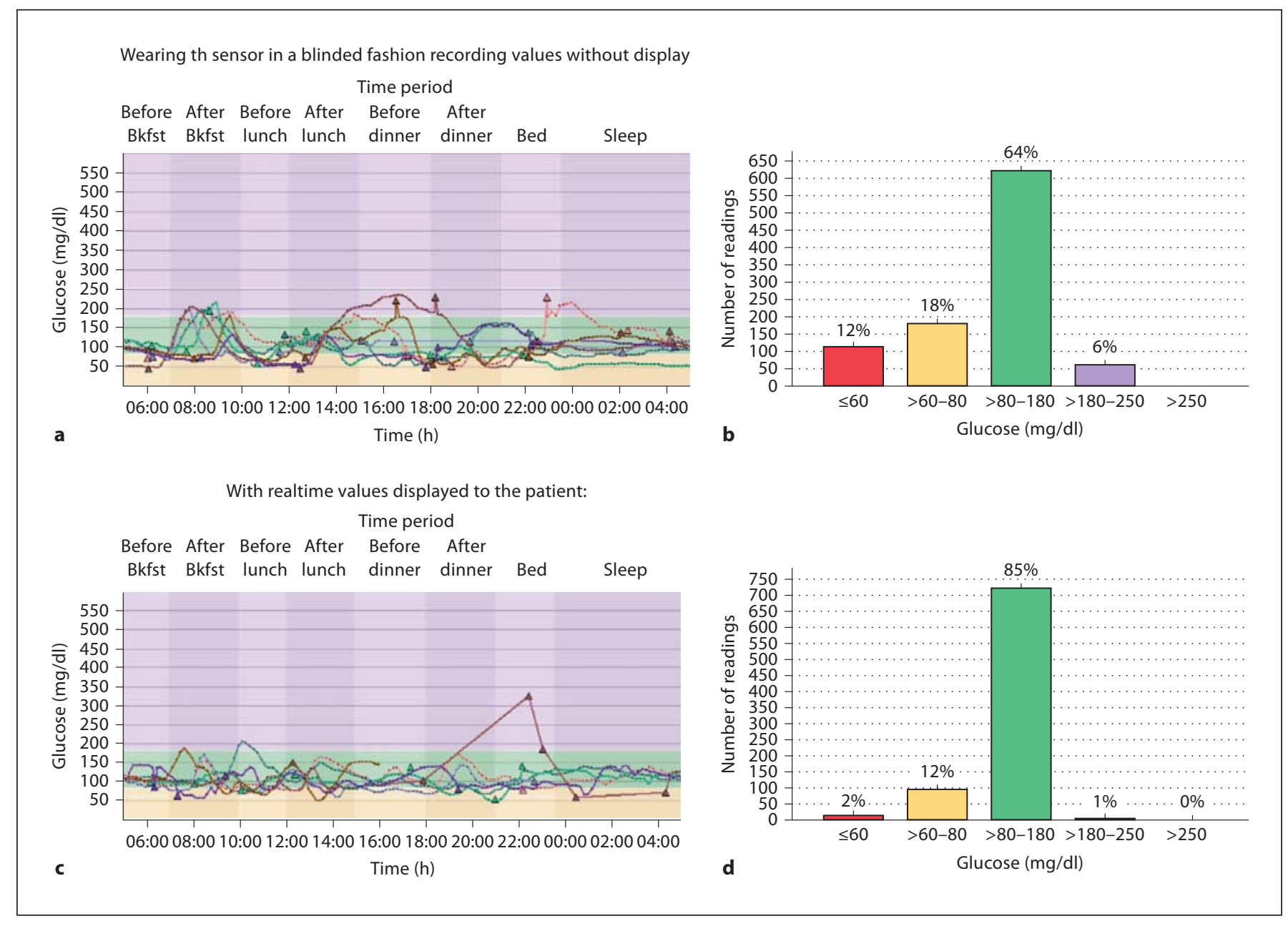

Fig. 1. Clinical benefit of 6 weeks realtime CGM with the Freestyle Navigator (Abbott Diabetes Care) in a patient with type 1 diabetes and hypoglycemia unawareness. Although the HbA1c remained stable (6.0 vs. $5.8 \%$ ) the patient experienced significantly less time in the hypo- and hyperglycemic range with a realtime display of glucose values $(\mathbf{c}, \mathbf{d})$ than during a previous 2 -week period wearing the sensor in a blinded fashion $(\mathbf{a}, \mathbf{b})$. mize glycemic variability [8]. A new measure of glycemia, derived from the duration of normal, low, and high readings, could supplement $\mathrm{HbAlc}$ as an integrated measure of control. Furthermore, measurements of MAGE [9], composite hypoglycemic score [10], and lability index [10] could provide information about the tendency for a mean blood glucose level to be comprised of stable or labile data points. For some patients, a decreased amount of glycemic instability alone, even without any improvement in $\mathrm{HbAlc}$, might represent an improved outcome (fig. 1). This mini-review describes the currently available technology and relevant pediatric studies of CGM on the basis of a Medline search (search strategy: CGM, children, diabetes).

\section{Types of Sensors}

Several CGMs have been approved by the US Food and Drug Administration (FDA) for use in the US or carry Conformité Européenne (CE) marking for use in Europe. They are the Continuous Glucose Monitoring System Gold (CGMS Gold; Medtronic MiniMed, Northridge, Calif., USA) [11], the GlucoWatch G2 Biographer (GW2B; Cygnus, Redwood City, Calif., USA) [12], the Guardian Telemetered Glucose Monitoring System (Medtronic MiniMed) [13], the GlucoDay (A. Menarini Diagnostics, Florence, Italy) [14], the Pendra (Pendragon Medical, Zurich, Switzerland) [15], the FreeStyle Navigator Continuous Glucose Monitor (Abbott Laborato- 

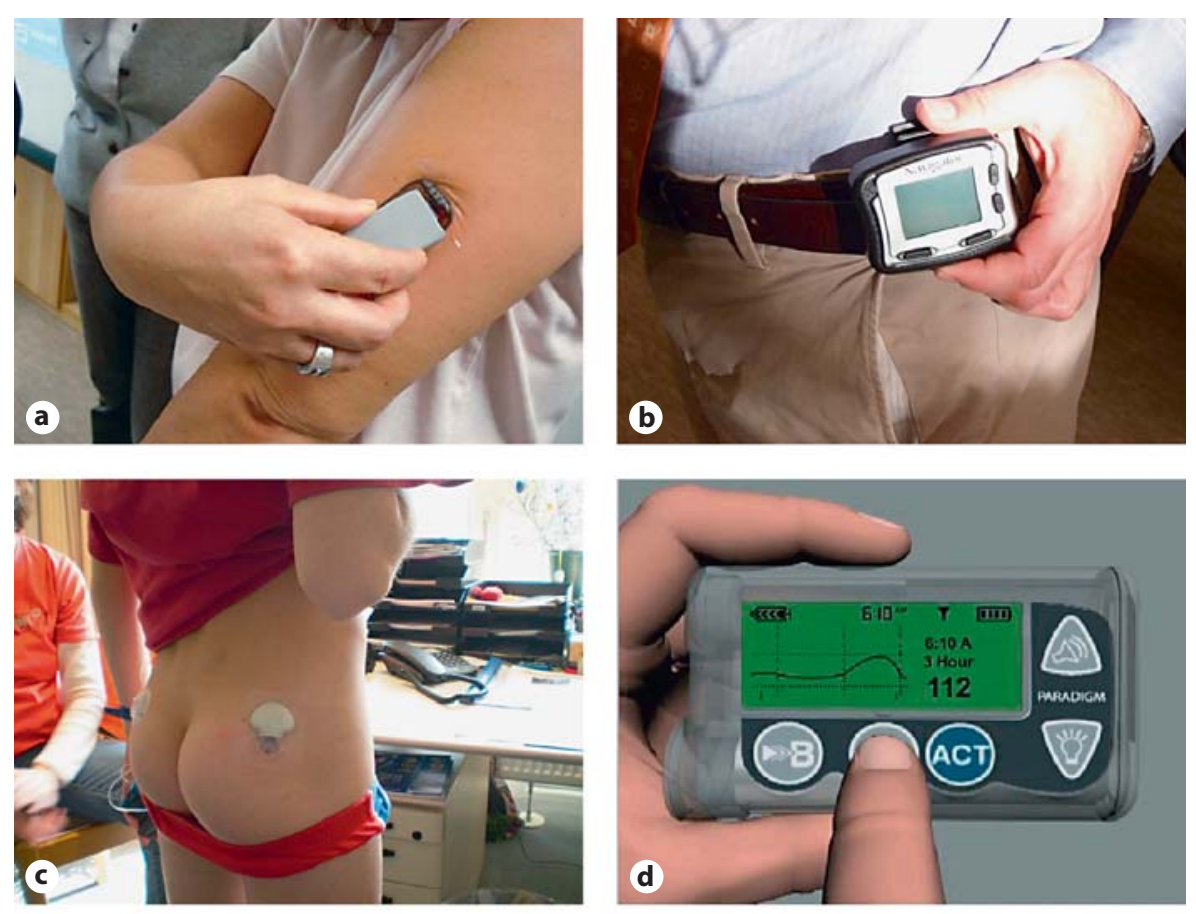

Fig. 2. Examples of CGM in the everyday practice. Placement of the sensor unit of the Freestyle Navigator (a) and wearing the receiver (b); placement of the Medtronic MiniLink (right) (c) and display of the Paradigm Realtime pump (d); the GlucoWatch Biographer (e); the Pendra watch (f); placement of the dialysis catheter of the Glucoday (g).
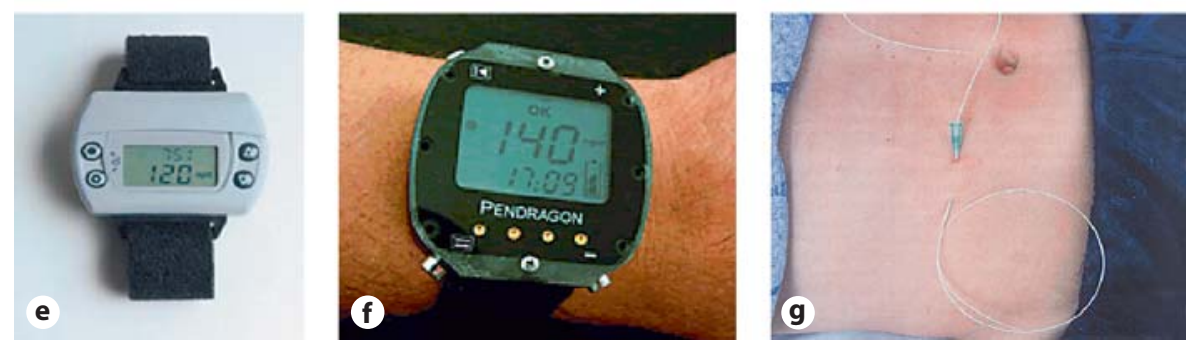

ries, Alameda, Calif., USA) [16] and the DexCom STS [17] (fig. 2, 3).

Particularly the development of the Pendra also shows the problem in evaluating these new technological approaches. In 2000 the Pendragon Medical Company introduced a truly noninvasive CGM device. This system was supposed to work through so-called impedance spectroscopy. Pendra was CE approved in May 2003. For a short time Pendra was available on the direct-to-consumer market. However, a post-marketing reliability study showed that several readings were erroneous [18] and potentially harmful to patients. Apparently marketing strategies had overtaken scientific progress in this device, contributing to the eventual disappearance of this monitor from the field. Currently four different systems are available outside the research setting (fig. 3).

Real-Time Glucose Sensors

\section{Where Is Glucose Measured?}

All designed prototypes or commercially available systems can be divided into three groups based on the way glucose measurement is carried out: noninvasive, minimally invasive, and invasive systems. Noninvasive devices use light or electromagnetic waves to measure glucose without penetrating the skin. Minimally invasive sensors measure the glucose concentration in the interstitial fluid of the skin or subcutaneous tissue.

\section{Noninvasive Glucose Sensors [19]}

While most wavelengths are absorbed through the skin [20], certain wavelengths can interact with the glucose molecule to allow optical [21] or near-infrared spec-

Horm Res 2008;70:193-202 


\begin{tabular}{|c|c|c|c|c|}
\hline & Guardian ${ }^{\circledR}$ REAL-Time & Paradigm ${ }^{\circledast}$ REAL-Time & DexCom STS ${ }^{\mathrm{TM}}$ & FreeStyle ${ }^{\circledR}$ Navigator \\
\hline Sensor size & 23 Gauge $(=0,6 \mathrm{~mm})$ & 23 Gauge $(=0,6 \mathrm{~mm})$ & 25 Gauge $(=0,5 \mathrm{~mm})$ & 22 Gauge $(=0,7 \mathrm{~mm})$ \\
\hline Sensor length & $12,7 \mathrm{~mm}$ & $12,7 \mathrm{~mm}$ & $13 \mathrm{~mm}$ & $6 \mathrm{~mm}$ \\
\hline Angle of placement & $45^{\circ}$ & $45^{\circ}$ & $45^{\circ}$ & $90^{\circ}$ \\
\hline Duration & $72 \mathrm{~h}$ & $72 \mathrm{~h}$ & 7 days & 5 days \\
\hline Time from placement to display & $2 \mathrm{~h}$ & $2 \mathrm{~h}$ & $2 \mathrm{~h}$ & $10 \mathrm{~h}$ \\
\hline Calibration & 2,8 , then every $12 \mathrm{~h}$ & 2,8, then every $12 \mathrm{~h}$ & $1,1.5$, every $12 \mathrm{~h}$ & $10,12,24,72 \mathrm{~h}$ \\
\hline New readings & every $5 \mathrm{~min}$ & every $5 \mathrm{~min}$ & every 5 min & every minute \\
\hline Display options & $3,6,12,24 \mathrm{~h}$ & $3,6,12,24 \mathrm{~h}$ & $1,3,9 \mathrm{~h}$ & $2,4,6,12,24 \mathrm{~h}$ \\
\hline Data download & possible & possible & possible & possible \\
\hline
\end{tabular}
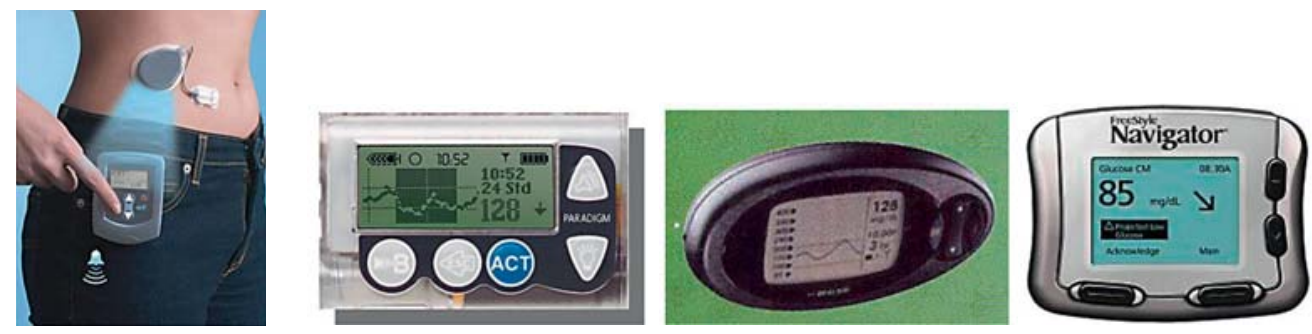

Fig. 3. Overview of the features of the continuous sensor systems that are commercially available.

troscopy [22]. Although some studies provide evidence for the good clinical correlation between blood glucose and spectroscopic results [23,24], ultrasound [25] or photoacoustic measurements [26], the limited strength of the signal and the low reliability of the measurement make the use of this approach currently impossible for clinical use [27].

Enzymatic glucose sensors are based on the enzymepromoted oxidation of glucose, with a generated signal that is proportional to the glucose concentration in the sensor environment. However, sensor accuracy can be impaired by oxygen deficit, chemical interference, enzyme inactivation and disturbances in the diffusion field in front of the sensor.

The minimally invasive device, called GlucoWatch ${ }^{\mathrm{TM}}$ Biographer (Cygnus, Redwood City, Calif., USA), is based on the principle of reverse iontophoresis, with generation of a signal in proportion to the interstitial glucose level [28]. The device provided near-continuous monitoring of glucose values in near real-time, and it is equipped with two types of alarms to detect hypoglycemia. It took a blinded phase of about $12 \mathrm{~h}$ to get a stable signal, displaying glucose values every $20 \mathrm{~min}$ for approximately the same time period thereafter. Skin reactions at the site of electrodes led to decreasing sensor use over time [29]. A clinical study of 89 children and adolescents using the GlucoWatch ${ }^{\mathrm{TM}}$ Biographer demonstrated an acceptable accuracy that may have been sufficient for detecting trends and modifying diabetes management [30]. However, use of the GlucoWatch ${ }^{\mathrm{TM}}$ Biographer in addition to standard glucose monitoring was not found to improve glycemic control or reduce the frequency of severe hypoglycemia over 6 months in 200 youths with type-1 diabetes when compared to results obtained with standard glucose monitoring alone. Despite its innovative technology, this monitor is currently no longer available.

\section{Microdialysis}

Systems with microdialysis are more or less invasive due to the introduction of the dialysis catheter into the tissue. They have been tried extensively for many years [31-33] with the Glucoday system having been most widely used. However, the subcutaneous insertion of the dialysis catheter and the size of the dialysis unit have limited the widespread use of this technology in children. 


\section{Subcutaneous Sensors}

Three subcutaneous enzymatic sensors in four systems are currently available. They differ in needle length, sensor wear, number of calibrations and time from placement to display (fig. 3). The Continuous Glucose Monitoring System (CGMS) by Medtronic-Minimed (Northridge, Calif., USA), was the first system approved by the FDA. The sensor is introduced through the skin and connected to a portable pager-size monitoring unit that records the sensor signal for several days [34]. The monitor records the signal from the sensor every $10 \mathrm{~s}$, then uses these readings to calculate and store the average value every $5 \mathrm{~min}$. Data are downloaded onto a computer and are presented as a continuous glucose level. The sensor signal must be calibrated against capillary blood glucose at least 3 times/day to match up correctly with blood glucose levels. The accuracy of the CGMS was assessed in 200 children and adolescents with type-1 diabetes when compared with reference serum glucose levels from a home glucose meter [35].

\section{The Old Technology - Holter-Type Retrospective Sensors}

The CGMS has been reported to serve as a tool to reveal daily glucose trends missed by self-monitoring of blood glucose (SMBG), to serve as an educational tool to improve metabolic control, and to decrease the rate and magnitude of hypoglycemia in young patients with type1 diabetes [36]. However, a recent meta-analysis [37] of five randomized pediatric studies [38-42] has indicated that the technology did not allow real-time assessment of glycemia by the patient, and that a retrospective analysis by the doctor also does not lead to a significant improvement in HbAlc. Nevertheless, the trials have already led to considerable practical experience with this technology. Age does not appear to be a limiting factor as these systems can also be applied in the preschool group [43]. Fourteen toddlers (age $3.9 \pm 0.8$ years) using CGM quarterly for 1 year when transitioned from multiple daily insulin with bedtime glargine to continuous subcutaneous insulin infusion (CSII) did not improve in Alc, whereas MAGE was reduced on CSII ( $210 \pm 31$ vs. $168 \pm 22 \mathrm{mg} /$ $\mathrm{dl}, \mathrm{p}<0.005)$. Although this study confirms that CSII improved glycemic instability without reducing $\mathrm{HbAlc}$, the quarterly application of CGM is not sufficient to improve overall control [44]. However, others have reported its usefulness in the management of individual patients, particularly adolescents experiencing difficulties with adherence to diabetes management and in detecting unrecognized hypoglycemia [45]. CGM can also be used to compare the effectiveness of various therapeutic strategies in research settings [46].

The power of CGM as a research tool was demonstrated by providing proof of the association of fluctuating blood glucose levels and behavioral changes that parents frequently report in their diabetic children. Comparing the results of a continuous glucose monitor over a 72hour period and a Behavior Assessment System for Children completed by the parents found a decrease in the externalizing behavior score of 1.0 for every $5 \%$ increase in time in the normal glycemic range, and for every $5 \%$ increase in time in the high glycemic range there was an increase in the externalizing behavior score of 1.0. There was no significant association between the monitoring of blood glucose and the mean internalizing behavior score. These findings underscore the importance of understanding the mechanisms of this association and how it might impact ultimate diabetes outcomes [47].

\section{The New Technology - Real-Time Sensors}

In contrast to the physician-based analysis of retrospective data on the Holter-type sensors, the real-time sensors shift the focus to the patient and the family, enabling them to react to subcutaneous glucose readings in a 'biofeedback' fashion. In a multicenter study with adult and pediatric participants [48] the efficacy of REALTime CGMS using the Guardian ${ }^{\circledR}$ RT system was evaluated in 81 children and adolescents with type-1 diabetes in whom glycemic control was suboptimal despite intensive insulin therapy. Patients were randomized to 1 of 3 groups: use of the sensor continuously; use for 3 days biweekly, or conventional SMBG (the control group). Treatment adjustments were made by physicians and patients on the basis of SMBG in the control group and on REALTime glucose profiles and alarms (of hypo- and hyperglycemia) in the 2 sensor groups. The results of the study demonstrated that REAL-Time CGMS using the Guardian ${ }^{\circledR}$ RT system improved glycemic control when compared with SMBG, especially in the group using the system continuously [48]. The continuous availability of glucose measurements permitted the patients to adjust their own insulin doses, food intake and physical activity and, thus, improve their glycemic control [49].

The Paradigm ${ }^{\circledR}$ 522/722 sensor-augmented insulin pump system is a fully external system designed to utilize 
Fig. 4. User evaluation on a seven-point Likert scale of an Integrated Insulin Pump and Real-Time Continuous Glucose Monitoring System in German pediatric and adult patients with type-1 diabetes [51].

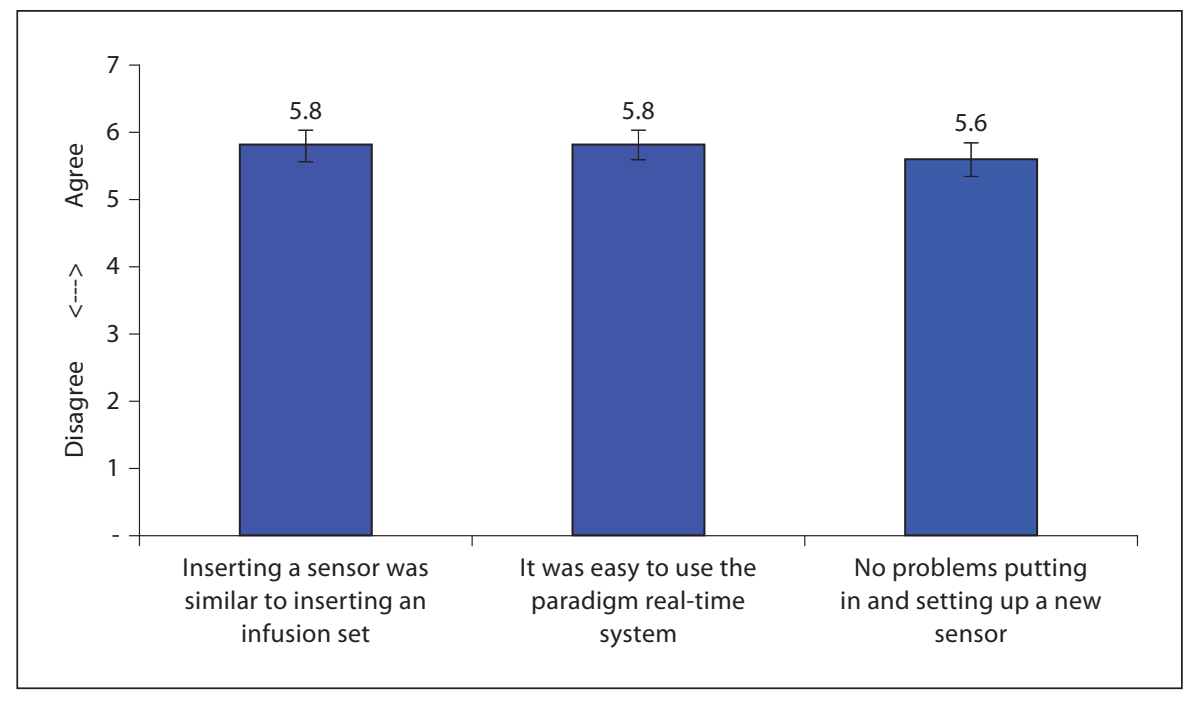

a subcutaneous glucose sensor, which is easily inserted under the skin, to continuously record blood sugar readings for up to 3 days. The system's transmitter is designed to send continuous glucose readings via radiofrequency to the pump, which is expected to display real-time glucose readings every $5 \mathrm{~min}$ and to provide trend graphs as well as hypoglycemia and hyperglycemia alerts to patients, allowing them to monitor trends in their blood sugar levels and make immediate corrective adjustments using their insulin pump.

A pilot trial of 1 month in 10 type- 1 diabetic children was reported in which the real-time CGMS and the insulin pump were combined into a sensor-augmented pump system [50]. In this short-term trial the system allowed access to real-time glucose values, trend data, and hypoglycemic and hyperglycemic alerts so that patients/parents, with the aid of the diabetes team, could adjust insulin doses, energy intake, and activity pattern to improve HbAlc level, and to reduce the frequency of episodes of hypoglycemia and hyperglycemia. This system was developed further and combined with an insulin pump in the Paradigm Realtime pump which we used in an user evaluation of 35 patients, 23 of them children, for 4 weeks (median age 10.5, range 3-15 years; diabetes duration 2, range $1-9$ years; CSII experience 1 , range $0.2-3$ years) [51]. 35 patients completed the 1-month evaluation, providing data from more than 1,000 patient-days. Patients ratings were high for overall satisfaction and ease of use of the system (fig. 4). The information given by the system was highly valued and demonstrated the feasibility of sensoraugmented pump therapy for all pediatric age groups.
This has lead to the conception of the ONSET-Trial. This international multicenter trial will compare the effect of conventional CSII with sensor-augmented pump therapy during the first year after onset of diabetes in 160 pediatric patients in a randomized prospective trial.

Pediatric experience is also available for the FreeStyle Navigator [52]. 30 insulin pump users with type-1 diabetes (average age 11.2 years) logging between 134 and 149 h/week of Navigator use improved their A1c from $7.1 \%$ at baseline to $6.8 \%$ at 13 weeks $(\mathrm{p}=0.02)$, and the percentage of glucose values between 71 and $180 \mathrm{mg} / \mathrm{dl}$ increased from 52 to $60 \%(\mathrm{p}=0.01)$ [53]. The Navigator was similarly tolerated over 13 weeks in 27 children aged 4-17 years using glargine-based multiple daily injection insulin regimens. Subjects averaged $>100 \mathrm{~h} /$ week of Navigator use. Mean HbAlc fell from $7.9 \pm 1.0 \%$ at baseline to $7.3 \pm 0.9 \%$ at 13 weeks $(p=0.004)$ [54].

The benefits of CGM are not limited to type-1 diabetes, but may also be helpful in type-2 diabetes (fig. 5) or other metabolic disorders [55]. Also, Guardian RT realtime subcutaneous blood glucose measurement is safe and potentially useful for CGM in critically ill children [56].

\section{Education: Time Lag, Calibration and Algorithms}

Teaching patients to determine what to do with all of the data provided by CGM remains challenging. Families previously relying on SMBG need to understand the difference of estimating the absolute blood glucose value 


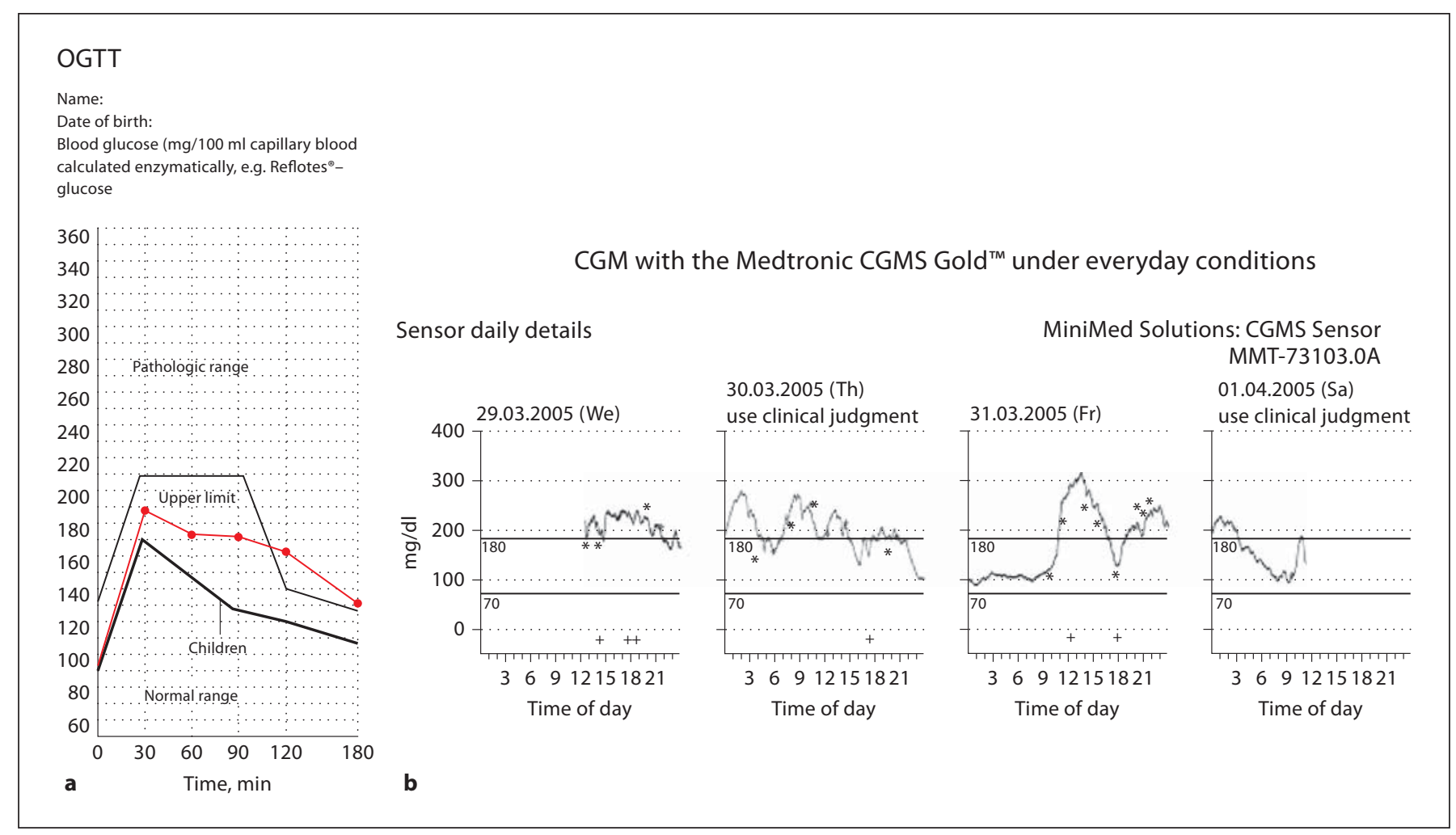

Fig. 5. Decision to intensify treatment in an 12-year-old obese boy $\left(\mathrm{BMI} 46 \mathrm{~kg} / \mathrm{m}^{2}\right)$ suspected of having type-2 diabetes despite a normal oral glucose tolerance test (OGTT; a). The CGMS readings (Medtronic; b) were in the diabetic range under everyday eating conditions. Metformin was started after CGM in connection with the laboratory results (HbA1c 6.3\%, insulin basal 95.5 (normal 5-30.0) $\mathrm{mU} / \mathrm{l}$, after $60 \mathrm{~min} 81.2 \mathrm{mU} / \mathrm{l})$. (point accuracy) and change in blood glucose (rate accuracy) and how to take into consideration the inherent interstitial time lag. All of the available sensors show a lower point accuracy compared to SMBG. However, a patient able to read trends in CGM will be able to live easily with this limitation when sufficient experience in analyzing glucose trends is available. Practical algorithms need to be developed to calculate the current and future insulin infusion/injection rates. Patient variability in assessing the glycemic excursion of the meal may also affect the function of such an open-loop system.

From the very beginning it is critical to understand the reasons for delays between glucose changes and a displayed value. For reasons that are currently not completely understood all subcutaneous sensors need a certain time after placement before they give a stable signal. Apparently, the trauma associated with subcutaneous insertion impairs glucose measurement for some time before reaching an equilibrium. Depending on the system this 'blind period' between placement and display of values ranges from 2 to $10 \mathrm{~h}$. In addition two further reasons for delay need to be considered: time for transfer of sample to detection site (i.e. microdialysis), and secondly time for analysis of the samples. A desired high frequency of glucose measurements, allowing detection of changes of 10 $\mathrm{mg} / \mathrm{dl}$ in $5 \mathrm{~min}$, is thought to be clinically relevant.

Even after an initial stable signal is reached, the reaction of the surrounding tissues with the sensor surface continues leading to changes in the sensor signal over time ('drift'). Repeated calibration may allow adjustment for drift for a certain period. Patients need to understand that the glucose measurements are in the interstitial fluid, and the lag time between blood and interstitial fluid sampled glucose levels may be in the range of 5-10 min.

Although accuracy has slightly improved with more calibrations, the timing of the calibrations appears more important. Modifying the algorithm to put less weight on daytime calibrations for nighttime values and calibrating during times of relative glucose stability may have greater impact on accuracy [57]. 


\section{Selecting the Right Patients for CGM}

In addition to proper education, patient selection may be a key to CGM success. The key to sensor success is the motivation to use it continuously. Already in early studies with the Glucowatch, more frequent use over a 6-month period was found among youths whose parents reported higher scores for treatment adherence and diabetes-related quality of life (QoL) at baseline. The study illustrates the empiric assessment of the psychological context of CGM use [58]. In a recent study of sensor-augmented pump therapy (SAP) in 40 CSII-experienced adolescents with $\mathrm{HbAlc}$ above $7.5 \%$, the improvement in $\mathrm{HbAlc}$ in the SAP group overall was not so different from controls: HbAlc baseline to 26 weeks $8.8 \pm 1.1$ to $8.0 \pm 1.1$ vs. control $8.6 \pm 0.8$ to $8.2 \pm 1.0$. However, if the improvement in $\mathrm{HbAlc}$ was analyzed in relation to sensor wear, a close association was seen: HbAlc difference with $<60 \%$ compliance $(\mathrm{n}=2)-0.3 \%$; 60-80\% ( $=5)-0.7 \%$; $>80$ $(\mathrm{n}=10)-1.0 \%(\mathrm{p}=0.0008)$ [59]. Therefore, psychological assessments about adherence with CGM may demonstrate the power of this technology much better that an uncritical application in unselected patients not all of whom use the information continuously. This observation is summed up in the phrase 'an expensive watch is not going to make you punctual unless you use it!'.

\section{Psychosocial Aspects of Sensor Use in Children}

In evaluating the psychosocial consequences of continuous use of sensors, the beneficial as well as adverse aspects for children and parents have to be assessed. CGMs could yield educational and motivational benefits or may lead to feelings of learned helplessness and frustration by information overload and continuous worries about the blood glucose level. These aspects have to be assessed by psychological questionnaires including the health-related QoL of the children, the parents' perception of their child's health-related QoL and the parents' own QoL or wellbeing, diabetes-related anxiety, treatment burden and parental stress. In addition the possible effects on behavioral problems, diabetes self-management skills and behavior, treatment satisfaction/tolerance of the sensor, and consequences for the mothers' or fathers' occupational situation should be considered.

One small study indicated a positive effect on the QoL of young children as judged by their parents through CGM. Particularly fear and behavior issues were influenced [44]. In another study [58] of older children and adolescents using the GlucoWatch G2, no significant effects on QoL or burden of the disease could be identified with the instruments used in that study. One has to take into consideration that in this study the CGM was used discontinuously and selected patients with a very good situation at baseline were studied. It remains to be clarified if conventional measures of fear, burden of the disease and QoL are sensitive enough to detect potential effects of CGM on psychosocial variables. Longer studies with continuous use of real-time sensors and sufficient power are currently lacking to evaluate the likely effects of sensor use on psychosocial aspects in children and their families.

\section{Closed Loop}

Several approaches have been used in the search for an 'artificial pancreas' [60-62]. The time lag remains also one of the major problems on the road to an artificial pancreas. In a research center setting a meal detection algorithm for 19 children 1-6 years old detected a meal at a mean time of $30 \mathrm{~min}$ from the onset of eating, at which time the mean serum glucose was $21 \mathrm{mg} / \mathrm{dl}$ above baseline (range $2-36 \mathrm{mg} / \mathrm{dl}$ ), although more than $90 \%$ of the meals were detected before the glucose had risen 40 $\mathrm{mg} / \mathrm{dl}$ from baseline [63]. In combination with the delay of subcutaneous insulin infusion, such a time lag remains a problem for automated insulin dosing in response to meals and ultimately the development of a closed loop system.

\section{Conclusions}

Nevertheless, it is our prediction that real-time CGM will become the standard of care for the treatment of pediatric patients with type-1 diabetes within the next 5-10 years [64]. However, in order to scientifically provide the promise of continuous sensing in children with type-1 diabetes, appropriate randomized prospective studies assessing this new technology in selected patients are needed. Psychological evaluation may be a key in identifying patients likely to wear a sensor continually. If the $\mathrm{HbAlc}$ is high at baseline, families may not be using the current tools adequately, and possibly sensor technology may be better for those with only modest A1c elevations. The ONSET trial will provide evidence for advocating this technology from the onset and thereby learning about diabetes in a feedback fashion. Early feedback from 
the first families to complete this study during the first year after the onset of diabetes shows that those families wish to continue with continuous real-time use after completion of the study and can easily imagine life-long use of continuous sensors. All in all, the emerging evi- dence for glycemic variability playing a role in such different areas as behavioral changes in children and the development of vascular complications underscores that additional endpoints to $\mathrm{HbAlc}$ need to be considered in future studies.

\section{References}

1 The effect of intensive diabetes treatment on the development and progression of longterm complications in adolescents with insulin-dependent diabetes mellitus: the Diabetes Control and Complications Trial. Diabetes Control and Complications Trial Research Group. J Pediatr 1994;125:177188 .

2 White NH, Cleary PA, Dahms W, Goldstein D, Malone J, Tamborlane WV; Diabetes Control and Complications Trial (DCCT)/ Epidemiology of Diabetes Interventions and Complications (EDIC) Research Group: Beneficial effects of intensive therapy of diabetes during adolescence: outcomes after the conclusion of the Diabetes Control and Complications Trial (DCCT). J Pediatr 2001; 139:804-812.

-3 Diabetes Research in Children Network (DirecNet) Study Group, Wilson DM, Kollman C: Relationship of A1C to glucose concentrations in children with type 1 diabetes: assessments by high frequency glucose determinations by sensors. Diabetes Care 2008;31: 381-385.

4 Heller S, Kim H, Draeger E: Within-person variation in fasting blood glucose is correlated to incidence of hypoglycemia in people with type 1 diabetes treated with insulin detemir and NPH insulin. Diabetologia 2004; 47S1:A303.

-5 Service FJ, Molnar GD, Rosevear JW, Ackermann E, Gatweood LC, Taylor WF: Mean amplitude of glycemic excursions, a measure of diabetic instability. Diabetes 1970;19: 644-655

-6 Saudek CD, Derr RL, Kalyani RR: Assessing glycemia in diabetes using self-monitoring blood glucose and hemoglobin A1c. JAMA 2006;295:1688-1697.

7 Danne T, Lange K, Kordonouri O: New developments in the treatment of type 1 diabetes in children. Arch Dis Child 2007;92: 1015-1019.

8 Brownlee M, Hirsch IB: Glycemic variability: a hemoglobin Alc-independent risk factor for diabetic complications. JAMA 2006; 295:1707-1708.

-9 Alemzadeh R, Loppnow C, Parton E, Kirby M: Glucose sensor evaluation of glycemic instability in pediatric type 1 diabetes mellitus. Diabetes Technol Ther 2003;5:167-173.

10 Ryan EA, Shandro T, Green K, Paty BW, Senior PA, Bigam D, Shapiro AM, Vantyghem
MC: Assessment of the severity of hypoglycemia and glycemic lability in type 1 diabetic subjects undergoing islet transplantation. Diabetes 2004;53:955-962.

11 Gross TM, Bode BW, Einhorn D, Kayne DM Reed JH, White NH, Mastrototaro JJ: Performance evaluation of the MiniMed continuous glucose monitoring system during patient home use. Diabetes Technol Ther 2000; 2:49-56.

12 Potts RO, Tamada JA, Tierney MJ: Glucose monitoring by reverse iontophoresis. Diabetes Metab Res Rev 2002;18(suppl 1):S49S53.

13 Bode B, Gross K, Rikalo N, Schwartz S, Wahl T, Page C, Gross T, Mastrototaro J: Alarms based on real-time sensor glucose values alert patients to hypo- and hyperglycemia: the guardian continuous monitoring system. Diabetes Technol Ther 2004;6:105-113.

14 Maran A, Crepaldi C, Tiengo A, Grassi G, Vitali E, Pagano G, Bistoni S, Calabrese G, Santeusanio F, Leonetti F, Ribaudo M, Di Mario U, Annuzzi G, Genovese S, Riccardi G, Previti M, Cucinotta D, Giorgino F, Bellomo A, Giorgino R, Poscia A, Varalli M: Continuous subcutaneous glucose monitoring in diabetic patients: a multicenter analysis. Diabetes Care 2002;25:347-352.

15 Pfuetzner A, Caduff A, Larbig M, Schrepfer T, Forst T: Impact of posture and fixation technique on impedance spectroscopy used for continuous and non-invasive glucose monitoring. Diabetes Technol Ther 2004;6: 435-441.

16 Feldman B, Brazg R, Schwartz S, Weinstein $\mathrm{R}$ : A continuous glucose sensor based on wired enzyme technology: results from a 3 day trial in patients with type 1 diabetes. $\mathrm{Di}$ abetes Technol Ther 2003;5:769-779.

17 Bailey TS, Zisser HC, Garg SK: Reduction in hemoglobin $\mathrm{A} 1 \mathrm{C}$ with real-time continuous glucose monitoring: results from a 12 -week observational study. Diabetes Technol Ther 2007;9:203-210

18 Wentholt IM, Hoekstra JB, Zwart A, DeVries JH: Pendra goes Dutch: lessons for the CE mark in Europe. Diabetologia 2005;48:10551058.

19 Klonoff DC: Noninvasive blood glucose monitoring. Diabetes Care 1997;20:433437.

20 Pickup J, McCartney L, Rolinski L, Birch D: In vivo glucose sensing for diabetes manage- ment: progress towards non-invasive monitoring. Interview by Judy Jones. BMJ 1999; 319:1289-1293.

-21 Heinemann L, Schmelzeisen-Redeker G: Non-invasive continuous glucose monitoring in type I diabetic patients with optical glucose sensors. Non-Invasive Task Force (NITF). Diabetologia 1998;41:848-854.

22 Gabriely I, Wozniak R, Mevorach M, Kaplan J, Aharon Y, Shamoon H: Transcutaneous glucose measurement using near-infrared spectroscopy during hypoglycemia. Diabetes Care 1999;22:2026-2032.

23 Robinson MR, Eaton RP, Haaland DM, et al: Noninvasive glucose monitoring in diabetic patients: a preliminary evaluation. Clin Chem 1992;38:1618-1622.

24 Heise HM, Lampen P: Transcutaneous glucose measurement using near-infrared spectroscopy: validation of statistical calibration models. Diabetes Care 2000;23:1208-1210.

25 Kost J, Mitragotri S, Gabbay RA, Pishko M, Langer R: Transdermal monitoring of glucose and other analytes using ultrasound. Nat Med 2000;6:347-350.

-26 Quan KM, Christison GB, Mackenzie HA, Hodgson P: Glucose determination by a pulsed photoacoustic technique: an experimental study using a gelatin-based tissue phantom. Phys Med Biol 1993;38:1911-1922.

27 Tamada JA, Garg SK, Jovanovic L, Pitzer KR, Fermi SJ, Potts RO: Noninvasive glucose monitoring: comprehensive clinical results. Cygnus Research Team. JAMA 1999;282: 1839-1844.

28 Garg SK, Potts RO, Ackerman NR, Fermi SJ, Tamada JA, Chase HP: Correlation of fingerstick blood glucose measurements with GlucoWatch biographer glucose results in young subjects with type 1 diabetes. Diabetes Care 1999;22:1708-1714.

29 Chase HP, Beck R, Tamborlane W, et al: A randomized multicenter trial comparing the GlucoWatch Biographer with standard glucose monitoring in children with type 1 diabetes. Diabetes Care 2005;28:1101-1106.

30 Tsalikian E, Kollman C, Mauras N, Weinzimer S, Buckingham B, Xing D, Beck R, Ruedy K, Tamborlane W, Fiallo-Scharer R; Diabetes Research in Children Network (DirecNet) Study Group: GlucoWatch G2 Biographer alarm reliability during hypoglycemia in children. Diabetes Technol Ther 2004;6:559-565. 
-31 Bolinder J, Ungerstedt U, Arner P: Longterm continuous glucose monitoring with microdialysis in ambulatory insulin-dependent diabetic patients. Lancet 1993;342: 1080-1085.

-32 Bolinder J, Hagstrom-Toft E, Ungerstedt U, Arner P: Self-monitoring of blood glucose in type I diabetic patients: comparison with continuous microdialysis measurements of glucose in subcutaneous adipose tissue during ordinary life conditions. Diabetes Care 1997;20:64-70

33 Hashiguchi Y, Sakakida M, Nishida K, Uemura T, Kajiwara K, Shichiri M: Development of miniaturized glucose monitoring system by combining a needle-type glucose sensor with microdialysis sampling method. Diabetes Care 1994;17:387-396.

34 Mastrototaro JJ: The MiniMed continuous glucose monitoring system. Diabetes Technol Ther 2000;2(suppl 1):s13-s18.

- 35 Tansey MJ, Beck RW, Buckingham BA, Mauras N, Fiallo-Scharer R, Xing D, Killman C, Tamborlane WV, Ruedy KJ; The Diabetes Research in Children Network (DirecNet) Study Group: Accuracy of the modified Continuous Glucose Monitoring System (CGMS) sensor in an outpatient setting: results from a diabetes research in children network (DirecNet) study. Diabetes Technol Ther 2005; 7:109-114.

- 36 Weintrob N, Schechter A, Benzaquen H, et al: Glycemic patterns detected by continuous subcutaneous glucose sensing in children and adolescents with type 1 diabetes mellitus treated by multiple daily injections vs. continuous subcutaneous insulin infusion. Arch Pediatr Adolesc Med 2004;158:677-684.

- 37 Golicki DT, Golicka D, Groele L, Pankowska E: Continuous Glucose Monitoring System in children with type 1 diabetes mellitus: a systematic review and meta-analysis. Diabetologia 2008;51:233-240.

- 38 Yates K, Hasnat Milton A, Dear K, Ambler G: Continuous glucose monitoring-guided insulin adjustment in children and adolescents on near-physiological insulin regimens: a randomized controlled trial. Diabetes Care 2006;29:1512-1517.

- 39 Lagarde WH, Barrows FP, Davenport ML, Kang M, Guess HA, Calikoglu AS: Continuous subcutaneous glucose monitoring in children with type 1 diabetes mellitus: a single-blind, randomized, controlled trial. Pediatr Diabetes 2006;7:159-164.

-40 Deiss D, Hartmann R, Schmidt J, Kordonouri $\mathrm{O}$ : Results of an randomized controlled cross-over-trial on the effect of continuous glucose monitoring (CGMS) on glycemic control in children and adolescents with type 1 diabetes. Exp Clin Endocrinol Diabetes 2006;114:63-67.

-41 Ludvigsson J, Hanas R: Continuous subcutaneous glucose monitoring improved metabolic control in pediatric patients with type 1 diabetes: a controlled cross-over study. Pediatrics 2003;11:933-938.
42 Chase HP, Kim LM, Owen SL, et al: Continuous glucose monitoring in children with type 1 diabetes. Pediatrics 2001;107:222226.

43 Gandrud LM, Xing D, Kollman C, Block JM, Kunselman B, Wilson DM, Buckingham BA: The Medtronic Minimed Gold continuous glucose monitoring system: an effective means to discover hypo- and hyperglycemia in children under 7 years of age. Diabetes Technol Ther 2007;9:307-316.

44 Alemzadeh R, Palma-Sisto P, Holzum M, Parton E, Kicher J: Continuous subcutaneous insulin infusion attenuated glycemic instability in preschool children with type 1 diabetes mellitus. Diabetes Technol Ther 2007;9:339-347.

45 Wiltshire EJ, Newton K, McTavish L: Unrecognised hypoglycaemia in children and adolescents with type 1 diabetes using the continuous glucose monitoring system: prevalence and contributors. J Paediatr Child Health 2006;42:758-763.

46 Deiss D, Kordonouri O, Hartmann R, Hopfenmüller W, Lüpke K, Danne T: Treatment with insulin glargine reduces asymptomatic hypoglycemia detected by continuous subcutaneous glucose monitoring in children and adolescents with type 1 diabetes. Pediatr Diabetes 2007;8:157-162.

-47 McDonnell CM, Northam EA, Donath SM, Werther GA, Cameron FJ: Hyperglycemia and externalizing behavior in children with type 1 diabetes. Diabetes Care 2007;30:22112215

48 Deiss D, Bolinder J, Riveline JP, Battelino T, Bosi E, Tubiana-Rufi N, Kerr D, Phillip M: Improved glycemic control in poorly controlled patients with type 1 diabetes using real-time continuous glucose monitoring. Diabetes Care 2006;29:2730-2732.

-49 Tubiana-Rufi N, Riveline JP, Dardari D: Real-time continuous glucose monitoring using GuardianRT: from research to clinical practice. Diabetes Metab 2007;33:415-420.

50 Halvorson M, Carpenter S, Kaiserman K, Kaufman F: A pilot trial in pediatrics with the sensor-augmented pump: combining real-time continuous glucose monitoring with the insulin pump. J Pediatr 2007;150: 103-105.

51 Danne T, Liebl A, Reicherl A, Walte K, Bacher F, Röthig K, Lauterborn R, Kordonouri $\mathrm{O}$ : First user experience with an integrated insulin pump and real-time continuous glucose monitoring system in pediatric and young adult patients with type 1 diabetes. Pediatr Diabetes 2006;7(suppl 5):65.

52 Wilson DM, Beck RW, Tamborlane WV, Dontchev MJ, Kollman C, Chase P, Fox LA Ruedy KJ, Tsalikian E, Weinzimer SA; DirecNet Study Group: The accuracy of the FreeStyle Navigator continuous glucose monitoring system in children with type 1 diabetes. Diabetes Care 2007;30:59-64.
53 Diabetes Research in Children Network (DirecNet) Study Group, Buckingham B, Beck RW, Tamborlane WV, Xing D, Kollman C, Fiallo-Scharer R, Mauras N, Ruedy KJ, Tansey M, Weinzimer SA, Wysocki T: Continuous glucose monitoring in children with type 1 diabetes. J Pediatr 2007;151:388-393, 393.e1-e2.

54 Weinzimer S, Xing D, Tansey M, FialloScharer R, Mauras N, Wysocki T, Beck R, Tamborlane W, Ruedy K; Diabetes Research in Children Network (DirecNet) Study Group: FreeStyle navigator continuous glucose monitoring system use in children with type 1 diabetes using glargine-based multiple daily dose regimens: results of a pilot trial Diabetes Research in Children Network (DirecNet) Study Group. Diabetes Care 2008;31:525-527.

55 Hershkovitz E, Rachmel A, Ben-Zaken H, Phillip M: Continuous glucose monitoring in children with glycogen storage disease type I. J Inherit Metab Dis 2001;24:863869.

56 Piper HG, Alexander JL, Shukla A, Pigula F, Costello JM, Laussen PC, Jaksic T, Agus MS: Real-time continuous glucose monitoring in pediatric patients during and after cardiac surgery. Pediatrics 2006;118:1176-1184.

57 Diabetes Research In Children Network (Direcnet) Study Group, Buckingham BA, Kollman C, Beck R, Kalajian A, Fiallo-Scharer R, Tansey MJ, Fox LA, Wilson DM, Weinzimer SA, Ruedy KJ, Tamborlane WV: Evaluation of factors affecting CGMS calibration. Diabetes Technol Ther 2006;8:318-325.

58 Diabetes Research in Children Network (DirecNet) Study Group: Psychological aspects of continuous glucose monitoring in pediatric type 1 diabetes. Pediatr Diabetes 2006; 7 : 32-38.

59 Buckingham B, Halvorson M, Kunselman E, Kaufmann FR: Sensor augmented pump therapy in adolescents: results of the first treat-to-target study. Diabetes 2007;56(suppl 1):A 479.

60 Updike SJ, Shults MC, Gilligan BJ, Rhodes RK: A subcutaneous glucose sensor with improved longevity, dynamic range, and stability of calibration. Diabetes Care 2000;23: 208-214.

61 Renard E: Implantable closed-loop glucosesensing and insulin delivery: the future for insulin pump therapy. Curr Opin Pharmacol 2002;2:708-716.

62 Hovorka R, Chassin LJ, Wilinska ME: Closing the loop: the ADICOL experience. Diabetes Technol Ther 2004;6:307-318.

63 Dassau E, Bequette BW, Buckingham BA, Doyle FJ: Detection of a meal using continuous glucose monitoring (CGM): implications for an artificial beta-cell. Diabetes Care 2008;31:295-300.

64 Klonoff DC: Continuous glucose monitoring: roadmap for 21st century diabetes therapy. Diabetes Care 2005;28:1231-1239. 